\title{
Hot Cracking Phenomena in Electron-beam-melted Surface Region of Co-Cr-Mo Alloy*
}

\author{
Shigeki Kakiuchi**, Shogo Tomida**, Hideki Yamagishi**, Takashi Yoneda*** and Kazuhiro Nakata****
}

The cause of hot cracking in Co-Cr-Mo (CCM) alloy induced by surface melting by electron beam (EB) irradiation was investigated for different EB currents. A regular pattern of linear grooves and ridges was formed by horizontal EB scanning with a square raster pattern. However, some irregular-shaped grooves also occurred. As the EB current was increased, these irregular grooves became larger and cracks appeared within them. Cross-sectional observations showed that the cracks occurred mainly in the heat-affected zone (HAZ) along grain boundaries and extended into the fused zone (FZ). The HAZ cracks terminated at grain boundary precipitates. The fractured surface of the cracks exhibited well-developed cellular-dendritic solidification structures in the FZ, indicating that these were solidification cracks. In contrast, the cracks in the HAZ had an immature dendritic structure with a relatively flat surface, typical of liquation cracks. It can be deduced that the cracks were caused by a liquid film remaining at the grain boundaries, and the driving force for crack propagation was shrinkage distortion caused by the fusion-solidification process.

Key Words: Electron beam, Co-Cr-Mo alloy, Hot cracking phenomena, Fractured surface, Grain boundary

\section{Introduction}

Co-Cr-Mo (CCM) alloys are often used for implant materials due to their good wear resistance ${ }^{1,2)}$. The sliding surfaces of the joints of these alloys are specular surfaces finished by the polishing process. However, CCM alloys are difficult materials to cut and polish. As a result, the use of machine finishing and hand polishing processes during manufacturing becomes too expensive. Therefore, one of the goals of this study was to save cost and reduce the time required for the polishing process.

The authors previously proposed the use of an electron beam (EB) surface-remelting process to improve the surface quality of as-cast CCM alloys ${ }^{3)}$. This processing method is highly energy efficient because reflection does not have a large influence, and surface oxidation is small because processing is carried out in a vacuum. However, in this process some cracks occurred in the remelted zone at the specimen surface due to rapid remelting and solidification. The reason for crack generation during this process is not yet clear.

In the present study, the surface of a CCM alloy casting material was remelted with EB irradiation under various conditions, and the resulting cracks were examined to reveal their origin.

* Received: 2012.11.29

** Member, Toyama Industrial Technology Center

*** Yoneda Advanced Casting Co., Ltd.

${ }^{* * * *}$ Member, Joining and Welding Research Institute, Osaka University

\section{Experimental procedures}

As-cast CCM alloy was used (Size: $30 \times 30 \times 5^{\mathrm{t}} \mathrm{mm}$ ) in this study. The composition is shown in Table 1. The surface roughness of the test pieces was adjusted to $\mathrm{Ra}=0.1-0.2 \mu \mathrm{m}$ by polishing.

An electron beam multi-surface machine (Tada Electric Co., Ltd., e-FM-0.4LB-1 VL-C5050) was used for the EB irradiation experiment. Schematic diagrams of the EB irradiation setup are shown in Fig. 1. A focused short-pulse EB was used to scan the test pieces and remelt their surface (Fig. 1A). A square raster EB irradiation pattern (EB irradiation area: $20 \times 20 \mathrm{~mm}$ ) was used (Fig. 1B). EB irradiation was performed under an accelerating voltage of $40 \mathrm{kV}$, a working distance of $200 \mathrm{~mm}$, a dot pitch of $0.02 \mathrm{~mm}$, and a clock frequency of $10 \mathrm{kHz}$. The exact focus position of the EB was the test piece surface. In this case, the diameter of the EB was approximately $0.2 \mathrm{~mm}$, and its scan speed was $12 \mathrm{~m} \cdot \mathrm{min}^{-1}$. The dot pitch, which is the distance between the centers of each dot-shaped EB irradiation area, was the same in the $\mathrm{X}$ and $\mathrm{Y}$ directions. The electron beam current was varied from 1 to $5 \mathrm{~mA}$. The pressure inside the vacuum chamber was less than $3 \mathrm{~Pa}$.

After EB irradiation, the remelted surface zone, its cross section, and the fractured surface of the cracks were examined by optical microscopy and scanning electron microscopy (SEM) together with energy-dispersive X-ray spectroscopy (EDS). In addition, CCM alloy structures were prepared by polishing and electro-etching at $6 \mathrm{~V}$ in a solution of methanol $(90 \mathrm{ml})$ and sulfuric acid $(10 \mathrm{ml})$. 
Table 1 Chemical composition of the as-cast Co-Cr-Mo alloy (mass\%).

\begin{tabular}{|c|c|c|c|c|c|c|c|c|c|c|c|c|c|c|}
\hline $\mathrm{Cr}$ & $\mathrm{Mo}$ & $\mathrm{Ni}$ & $\mathrm{Fe}$ & $\mathrm{C}$ & $\mathrm{Si}$ & $\mathrm{Mn}$ & $\mathrm{W}$ & $\mathrm{P}$ & $\mathrm{S}$ & $\mathrm{N}$ & $\mathrm{Al}$ & $\mathrm{Ti}$ & $\mathrm{B}$ & $\mathrm{Co}$ \\
\hline 28.35 & 6.03 & 0.05 & 0.16 & 0.10 & 0.58 & 0.51 & 0.03 & $<0.001$ & $<0.001$ & 0.17 & 0.03 & 0.01 & $<0.001$ & $\mathrm{Bal}$. \\
\hline
\end{tabular}

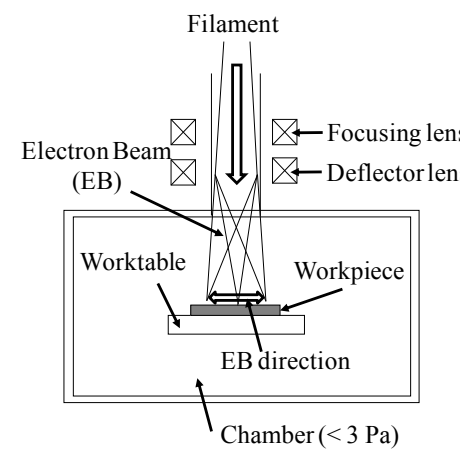

(A)

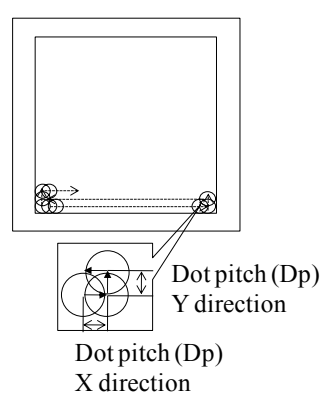

(B)
Fig. 1 Schematic diagrams of EB irradiation test.

(A: EB irradiation equipment, B: Square raster pattern)

\section{Results and discussion}

Optical and SEM micrographs of the as-cast CCM alloy are shown in Fig. 2. As seen in Fig. 2A, the CCM alloy used in this study had a large grain size. In Figs. 2B and 2C, globular precipitates can be observed between dendrites, and in Fig. 2D, fine precipitates can be seen along the grain boundaries. A large part of precipitates along the grain boundary are not globular precipitates, but fine precipitates in Figs. 2C and 2D.

SEM images and EDS spectra obtained from the as-cast CCM alloy are shown in Fig. 3. More $\mathrm{Cr}$ and Mo but less Co are seen in the globular precipitate region (Fig. 3B) compared with the matrix (Fig. 3A). In addition, more $\mathrm{Cr}$ but less Co is seen in the fine precipitate region (Fig. 3C) within the grain boundary compared with the matrix. It is assumed that both the globular precipitates and the grain boundary precipitates correspond to the $\sigma$-phase ${ }^{4-9)}$ (Mo-containing Co-Cr intermetallic compound) ${ }^{7)}$ that was crystallized by segregation of the solute elements when the cooling rate was low. Mo may have dissolved into the grain boundary precipitates.

A ternary phase diagram of the liquidus projection for Co-Cr-Mo system ${ }^{10)}$ is shown in Fig. 4. The CCM alloy is a eutectic-type alloy, with the eutectic point $\mathrm{E}$ given by $\mathrm{L} \Leftrightarrow(\mathrm{Co}$ $(\mathrm{HT}))+\mathrm{CoCr}(\mathrm{LT})+\mathrm{Co}_{7} \mathrm{Mo}_{6}$, where $\mathrm{L}$ represents the liquid phase. This indicates that solidification of the CCM alloy from the liquid phase into $\mathrm{Co}, \mathrm{CoCr}$, and $\mathrm{Cr}_{7} \mathrm{Mo}_{6}$ is completed at the ternary eutectic point. The temperature of the liquidus line decreases with increasing $\mathrm{Cr}$ and Mo content.
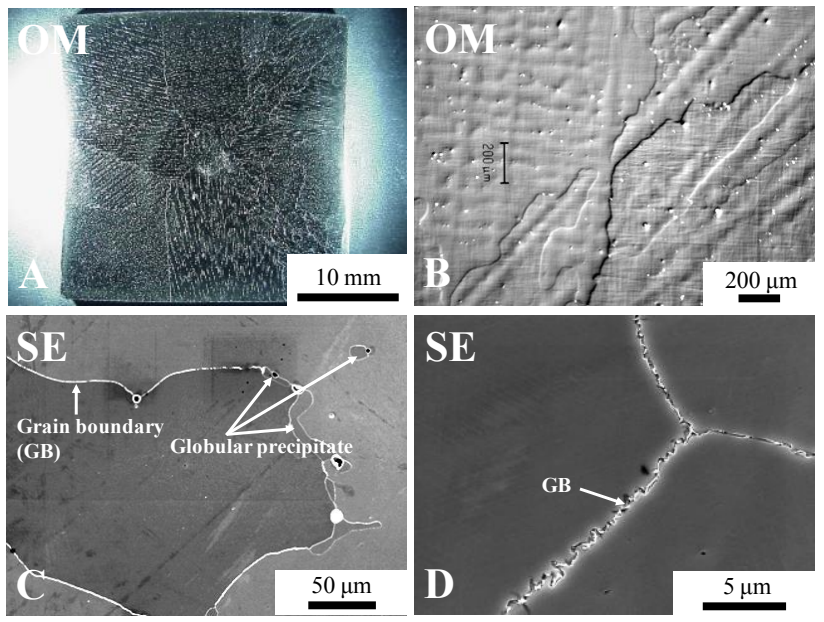

Fig. 2 Optical (OM) and SEM (SE) micrographs of the as-cast Co-Cr-Mo alloy.

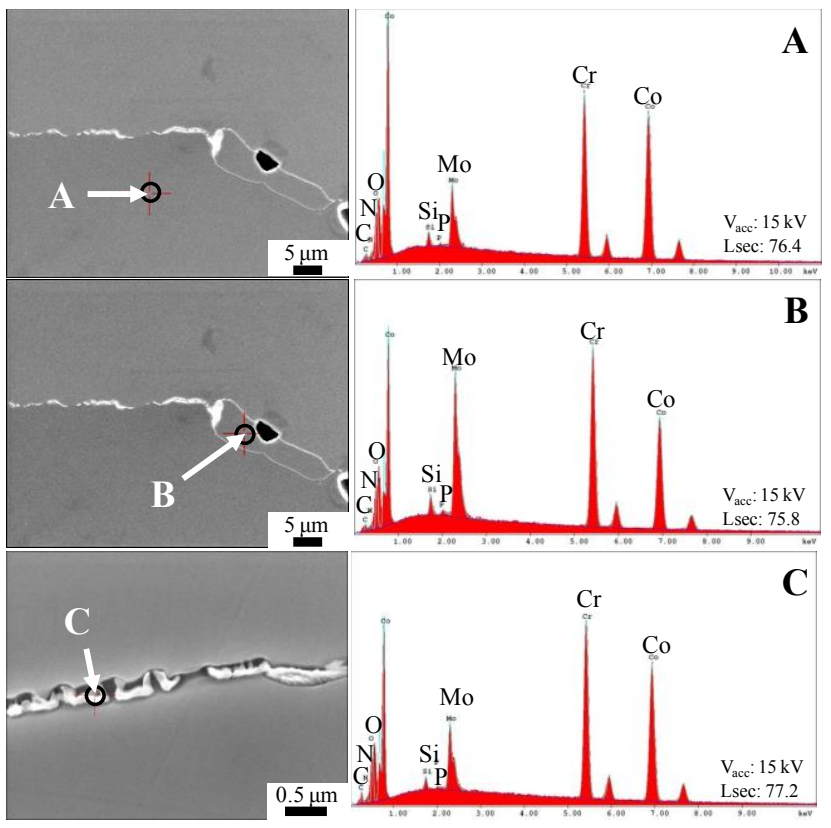

Fig. 3 SEM images and EDS spectra of the as-cast CCM alloy, A: matrix, B: globular precipitate, C: fine precipitate in grain boundary.

SEM micrographs of the CCM alloy in the remelted surface after horizontal EB scanning with a square raster pattern are shown in Fig. 5. The EB current was $1 \mathrm{~mA}$ in Figs. 5A and 5B, and $3 \mathrm{~mA}$ in Figs. 5C and 5D. As seen in Figs. 5A and 5C, a regular pattern of linear grooves and ridges aligned in the same direction was formed on each of the surfaces. However, irregularly shaped grooves running in different directions were also produced. As the EB current was increased, the shape of these grooves became more clear. The cracks that were present within the irregular grooves can be clearly seen in the higher magnification images shown in Figs. 
$5 \mathrm{~B}$ and $5 \mathrm{D}$. The cracks produced at $3 \mathrm{~mA}$ were longer than those produced at $1 \mathrm{~mA}$.

Figs. $6 \mathrm{~A}$ and $6 \mathrm{~B}$ show the influence of the EB current on the total crack length and the number of cracks, respectively, on the remelted surface. When the EB current was increased from 1 to 2 $\mathrm{mA}$, the total crack length increased noticeably from 0.18 to 15.8 $\mathrm{mm}$ and the number of cracks also showed a remarkable increase from 8 to 235 . Both the crack length and the number of cracks peaked for an EB current of $2 \mathrm{~mA}$, and then decreased, though still remaining high.

Cross-sectional SEM micrographs of the CCM alloy after EB irradiation with a current of 1 and $3 \mathrm{~mA}$ are shown in Figs. 7A and $7 \mathrm{~B}$, respectively. Here, the heat-affected zone (HAZ) is defined as the area between the fusion boundary (FB) and the crack tip. As the EB current was increased from 1 to $3 \mathrm{~mA}$, the width of the fused zone (FZ) increased from 25 to $82 \mu \mathrm{m}$. In both cases, the FZ had a fine cellular-dendritic solidification structure, which indicated that the solidification rate after remelting was extremely high. As seen in Fig. 7A, at an EB current of $1 \mathrm{~mA}$, a crack occurred at a grain boundary in the HAZ below the FZ. This crack terminated at the FB of the FZ. However, at $3 \mathrm{~mA}$, cracks occurred not only at grain boundaries in the HAZ, but also in the FZ. Some of the HAZ cracks terminated at the FB, but other large cracks extended into the FZ and reached the surface. The width of the crack generation region in the HAZ increased with increasing EB current in a similar manner to that in the FZ. The morphology of the cracks in the HAZ and FZ suggests that cracks are generated in the HAZ along grain boundaries in the base metal (BM).

SEM micrographs of the fractured surface of a crack are shown in Fig. 8 for an EB current of $3 \mathrm{~mA}$. Figs. 8B, 8C, and 8D show higher-magnification SEM micrographs of the three regions indicated in Fig. 8A, which correspond to solidification cracking in the FZ, liquation cracking in the HAZ, and artificial fracturing in the BM, respectively. In the upper zone near the surface, as shown in Fig. 8B, the fractured surface exhibits a well-developed cellular-dendritic solidification structure, which is typical of solidification cracking in the FZ. The depth of this zone from the surface is approximately $70 \mu \mathrm{m}$ in Fig. $8 \mathrm{~A}$, corresponding to the depth of the FZ in Fig. 7B. In the narrow central zone with a width of approximately $20 \mu \mathrm{m}$ in Fig. $8 \mathrm{C}$, an immature dendritic pattern with a relatively flat surface is observed. This suggests that the fractured surface of the crack is the result of liquation cracking in the HAZ. In the lower zone, a fine dimple pattern can be observed in Fig. 8D. This appeared in the artificially fractured surface of the BM that was made for SEM observation of the crack surface as a result of being subject to bending stress. Therefore, the liquation cracks did not in fact form in this region. Based on these results, it can be assumed that the cracks were caused by a liquid film remaining at the grain boundaries in both the FZ and the HAZ.

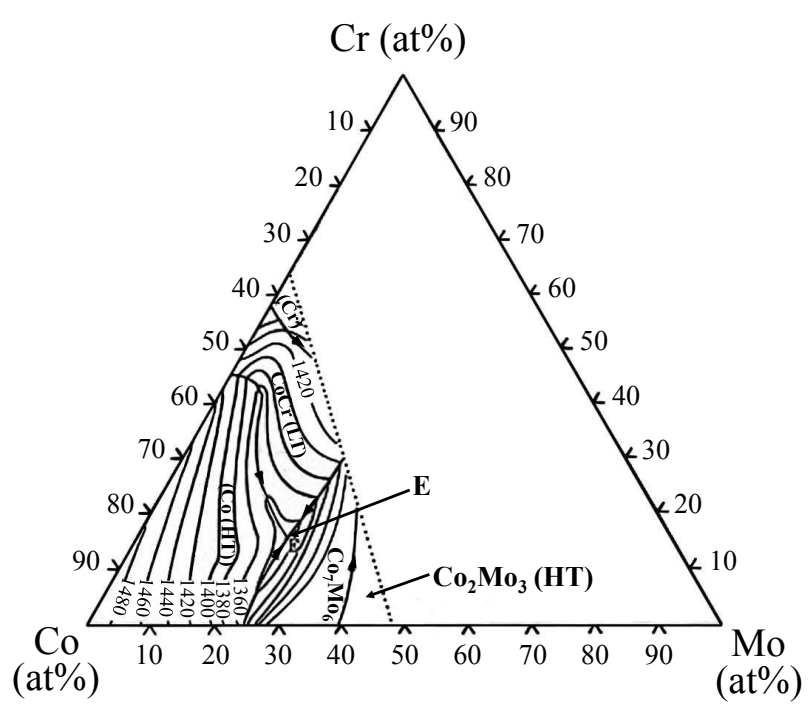

Fig. 4 Ternary phase diagram of liquidus projection for Co-Cr-Mo system.
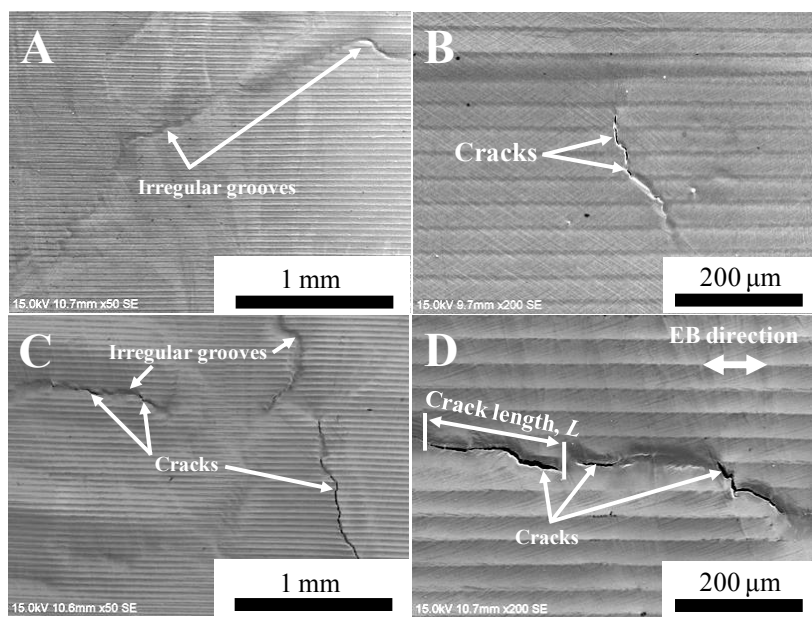

Fig. 5 SEM images of surface of CCM alloys after EB irradiation (A, B: $I_{\mathrm{EB}}=1 \mathrm{~mA}, \mathrm{C}, \mathrm{D}: I_{\mathrm{EB}}=3 \mathrm{~mA}$ ).
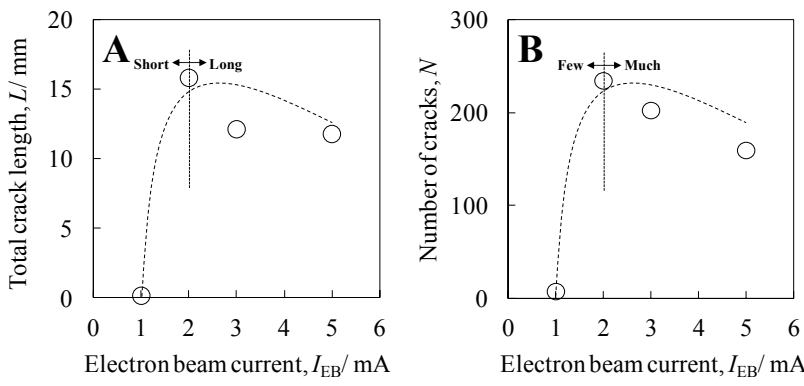

Fig. 6 Influence of EB current on A: total crack length, B: number of cracks measured on CCM alloys surface after EB irradiation.

Cross-sectional SEM micrographs of the FZ in the CCM alloy are shown at different magnifications in Fig. 9 for an EB current of $3 \mathrm{~mA}$. These images indicate that the cracks extend through the FZ and the HAZ and terminate at fine grain boundary precipitates in the BM. Partial liquation at the grain boundaries may have occurred as a result of these precipitates. 


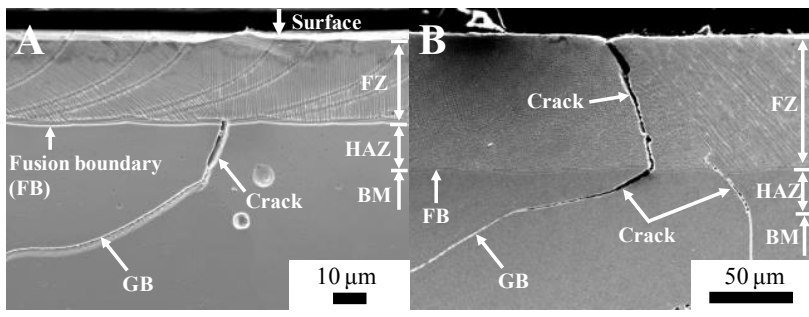

Fig. 7 Cross-sectional SEM micrographs of CCM alloys after EB irradiation (A: $\left.I_{\mathrm{EB}}=1 \mathrm{~mA}, \mathrm{~B}: I_{\mathrm{EB}}=3 \mathrm{~mA}\right)$.

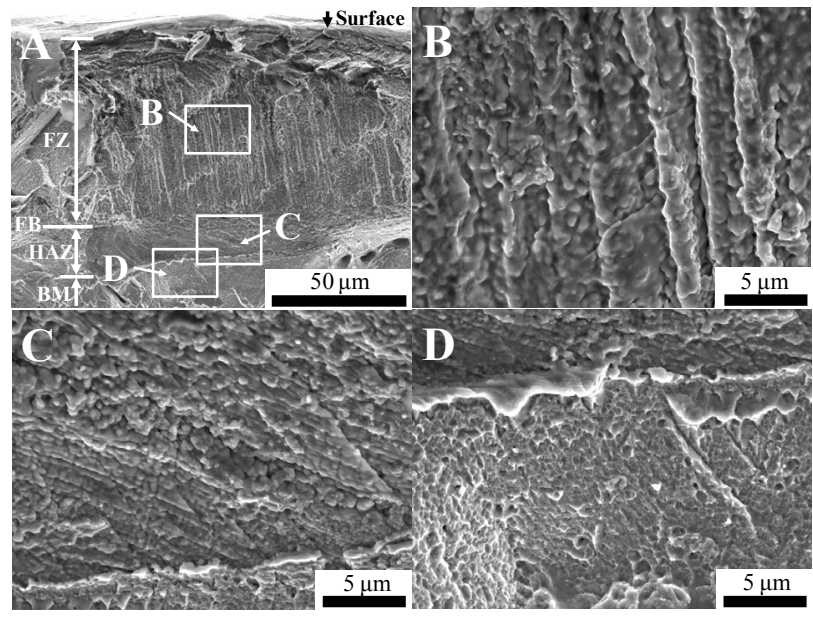

Fig. 8 Fractured surface of crack generated in the CCM alloy after EB remelting $\left(I_{\mathrm{EB}}=3 \mathrm{~mA}\right)$.

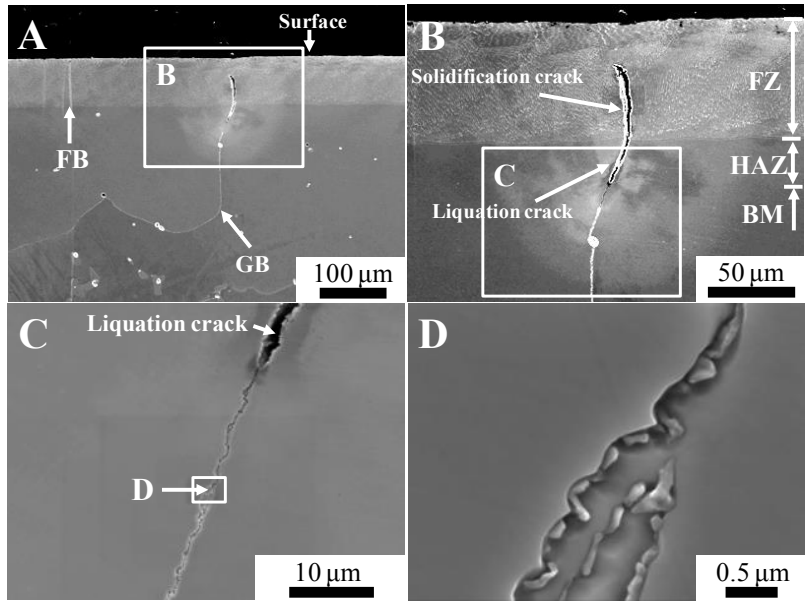

Fig. 9 Cross-sectional SEM micrographs of the CCM alloy after EB irradiation $\left(I_{\mathrm{EB}}=3 \mathrm{~mA}\right)$

\section{Conclusions}

The surface of a CCM alloy cast material was remelted by EB irradiation with different EB currents, and an investigation was carried out into hot cracking phenomena on the remelted surface, cross section, and fractured surface of the cracks themselves in relation to microstructures. The following results were obtained: (1) As the EB current was increased from 1 to $2 \mathrm{~mA}$, both the total crack length and the number of cracks strongly increased in the remelted surface region of the as-cast CCM alloy.
(2) The cracks occurred mainly in the HAZ along the grain boundaries, and some extended into the FZ. These HAZ cracks terminated at grain boundary precipitates.

(3) Two types of cracks were observed; these were solidification cracks in the $\mathrm{FZ}$ and liquation cracks in the HAZ.

\section{Acknowledgements}

This work was performed as part of the Joint Research Program of Joining and Welding Research Institute of Osaka University. It was also performed as part of the Supporting Industry Programs project, "Development of new solidification structure control technology for the high-development of precision casting processes" coordinated by the Ministry of Economy, Trade and Industry.

\section{References}

1) A. Chiba, K. Kumagai, N. Nomura and S. Miyakawa: Pin-on-disk wear behavior in a like-on-like configuration in a biological environment of high carbon cast and low carbon forged Co-29Cr-6Mo alloys, Acta Materialia, 55 (2007), 1309-1318.

2) K. Kumagai, N. Nomura, T. Ono, M. Hotta and A. Chiba: Dry Friction and Wear Behavior of Forged Co-29Cr-6Mo Alloy without $\mathrm{Ni}$ and C Additions for Implant Applications, Materials Transactions, 46 (2005), 1578-1587.

3) S. Kakiuchi, S. Tomida, H. Yamagishi, T. Nagae and T. Yoneda: Effect of the process conditions on the surface quality of $\mathrm{Co}-\mathrm{Cr}-\mathrm{Mo}$ alloy with the surface melting process by electron beam, Preprints of the National Meeting of Japan Welding Society, 91 (2012), 8-9. (in Japanese)

4) A. Chiba, N. Nomura and Y. Ono: Microstructure and mechanical properties of biomedical $\mathrm{Co}-29 \mathrm{Cr}-8 \mathrm{Mo}$ alloy wire fabricated by a modified melt-spinning process, Acta Materialia, 55 (2007), 2119-2128.

5) J. V. Giacchi, C. N. Morando, O. Fornaro and H. A. Palacio: Microstructural characterization of as-cast biocompatible Co-Cr-Mo alloys, Materials Characterization, 62 (2011), 53-61.

6) S. Kurosu, N. Nomura and A. Chiba: Effect of Sigma Phase in Co-29Cr-6Mo Alloy on Corrosion Behavior in Saline Solution, Materials Transactions, 47 (2006), 1961-1964.

7) K. Yamanaka, M. Mori and A. Chiba: Mechanical properties of as-forged $\mathrm{Ni}$-free $\mathrm{Co}-29 \mathrm{Cr}-6 \mathrm{Mo}$ alloys with ultrafine-grained microstructure, Materials Science and Engineering A, 528 (2011), 5961-5966.

8) L. E. Ramirez-Vidaurri, M. Castro-Roman, M. Herrera-Trejo, C. V.Garcia-Lopez and E. Almanza-Casas: Cooling rate and carbon content effect on the fraction of secondary phases precipitate in as-cast microstructure of ASTM F75 alloy, Journal of Materials Processing Technology, 209 (2009), 1681-1687.

9) A. Chiba: Development of Highly-functional Co-based Alloys for Biomedical Applications, Materia Japan, 46(3) (2007), 194-197. (in Japanese)

10) P. Villars, A. Prince and H. Okamoto: Handbook of Ternary Alloy Phase Diagrams, 6 (ASM, 1995), 8121. 